\title{
Antenatal and neonatal factors contributing to extra uterine growth failure (EUGR) among preterm infants in Boston Birth Cohort (BBC)
}

\author{
Kartikeya Makker $\mathbb{D}^{1} \cdot$ Yuelong $\mathrm{Ji}^{2} \cdot$ Xiumei $\mathrm{Hong}^{2} \cdot$ Xiaobin Wang $\mathrm{W}^{2,3}$
}

Received: 25 August 2020 / Revised: 16 November 2020 / Accepted: 20 January 2021 / Published online: 15 February 2021

(c) The Author(s), under exclusive licence to Springer Nature America, Inc. 2021

\begin{abstract}
Objective Identify antenatal and neonatal factors associated with primary outcome of EUGR.

Methods 1063 preterm infants from a subset of the BBC were included in this prospective cohort study. Regression analysis was carried out to evaluate associations of EUGR with antenatal factors and neonatal factors.

Results $6.1 \%$ of the infants had in-utero growth restriction (IUGR) at birth and $21.7 \%$ of infants had EUGR. The adjusted odds ratio for EUGR status were significant for birth weight (OR 0.99, $p=0.00$, CI 0.99-0.99), for GA at birth (OR 4.58, $p=0.00$, CI 3.25-6.44), for PDA (OR 2.9, $p=0.02$, CI 1.17-7.1), for NEC (OR 5.14, $p=0.012$, CI 1.44-18.3) and for day of life of reaching full feeds (OR 1.04, $p=0.001$, CI 1.01-1.06).

Conclusion This study highlights important factors associated with EUGR. Additional studies are needed to gain further insight.
\end{abstract}

\section{Introduction}

Preterm infants are commonly diagnosed as having "extra uterine growth restriction" (EUGR) or "postnatal growth failure" (PGF) when weight at discharge or around 36-40 weeks postmenstrual age is below the 10th percentile $(z$-score $\leq 1.28)[1,2]$. Numerous studies show that very very low birth weight $(<1000 \mathrm{~g})$ and extremely low birth weight $($ ELBW) $(<750 \mathrm{~g})$ infants often remain physically smaller than term-born peers during infancy and well into childhood [3].

Data from the National Institute of Child and Human Development (NICHD) Neonatal Research Network indicate

Supplementary information The online version contains supplementary material available at https://doi.org/10.1038/s41372021-00948-4.

Kartikeya Makker

kmakker1@jhmi.edu

1 Division of Neonatology Department of Pediatrics, Johns Hopkins School of Medicine, Baltimore, MD, USA

2 Center on the Early Life Origins of Disease, Department of Population Family and Reproductive Health, Johns Hopkins Bloomberg School of Public Health, Baltimore, MD, USA

3 Division of General Pediatrics, Department of Pediatrics, Johns Hopkins School of Medicine, Baltimore, MD, USA that $16 \%$ of ELBW infants are small for gestational age (SGA) at birth, but by 36 weeks corrected age $~ 89 \%$ have growth failure depicting high rates of poor postnatal growth during neonatal intensive care (NICU) exposures [4]. EUGR is a medical problem with long term health consequences into later childhood and adulthood [5, 6]. Several studies have shown the association between poor postnatal growth and an increased morbidity and mortality both in the neonatal period and in later life [7-9]. EUGR also influences neurodevelopmental outcomes of ELBW [10], and may have significant effects on cardio-metabolic health (insulin resistance, diabetes mellitus, hypertension) in later childhood and even adulthood [11-13]. As such, understanding and optimizing preterm infant's growth during NICU stay remains an important topic, with short- and long-term health implications for the infant.

At present some data are available on what antenatal or neonatal factors affect extra uterine growth during NICU but there are very few studies that have assessed both antenatal and neonatal factors and their impact on EUGR in NICU. Factors that have been identified for IUGR include maternal factors, such as pregnancy-induced hypertension, infection, and substance use such as smoking [14]; fetal factors, such as chromosomal abnormality or genetic factors and placental factors, such as gross structural abnormality or single umbilical artery $[15,16]$.

Factors reportedly associated with EUGR have included male gender, need for assisted ventilation prolonged need 
for respiratory support, length of hospital stay, and the development of neonatal morbidities [17-19]. Feeding and nutrition practices are suspected to contribute to growth failure in the NICU and current standardization of NICU feeding practices has led to some reduction in growth failure rates [20-22]. However, it still underscores the need to identify other factors responsible for EUGR in preterm infants during NICU stay. Many complications experienced by the preterm infants in the NICU like late onset sepsis and necrotizing enterocolitis (NEC) [20] have been implicated in leading to EUGR but possibly some antenatal factors may also have a role to play not only in IUGR but also EUGR. Another factor that has not been adequately explored is placental pathology. Placental pathology findings are known to impact in utero growth but have not been extensively studied as a factor for preterm infants, specifically during the NICU stay [23-25]. In summary, there is a significant knowledge gap related to important contributors to EUGR during NICU stay. An investigation into role of factors on EUGR in NICU would be of significance in management of this fragile population and its significance is well beyond neonatal period, given the strong evidence of early growth failure and chronic diseases later in life [26]. In this study, we sought to describe the dynamic growth patterns of the preterm birth from in-utero to NICU discharge. Additionally, we intended to explore the antenatal and neonatal factors that increase the risk of NICU growth failure assessed at NICU discharge. We aim to analyze the effects of both antenatal and neonatal factors on EUGR in a prospective cohort study sample to best tease out the factors that would independently associated with EUGR.

\section{Materials and methods}

The study protocol was approved by the institutional review boards of Boston University Medical Center and the Johns Hopkins Bloomberg School of Public Health. Written informed consent was obtained from the mothers. The study sample for this report included 1063 mother-infant pairs enrolled within 2-3 days after birth, who were a subset of the Boston Birth Cohort (BBC), a predominately African American, urban, low-income minority population initiated in 1998 under rolling enrollment at Boston Medical Center [14]. The participating children for the analysis were born between 1998 and 2010 who received care in the NICU. The exclusion criteria for initial enrollment included multiple-gestation pregnancies (e.g., twins and triplets) and newborns with major birth defects.

The primary outcome (dependent variable) is growth pattern assessed at birth and at NICU discharge. We analyzed neonatal growth patterns at two time points: at admission to NICU (right after birth) and at NICU discharge. By studying growth pattern at two time points, we were also able to evaluate the dynamics of neonatal growth patterns over the NICU stay, and factors contributes to the NICU growth trajectory. Growth pattern at birth is based on birthweight for gestational age that is categorized into three groups: SGA $(<10$ th percentile), large for gestational age (LGA) ( $>90$ th percentile), and appropriate for gestational age (AGA) (10th-90th percentile) according to an established local sex and race-specific reference population [27]. Growth pattern at NICU discharge is based on infant weight for corrected gestational age (SGA, AGA, LGA) per Fenton classification [28]. Antenatal steroid intake was collected as none vs at least 1 dose vs. $\geq 2$ doses [29].

Maternal covariables were defined based on a standard maternal questionnaire interview. Race/ethnicity was based on maternal response to fixed categories in the questionnaire and classified as black and non-black. Maternal smoking during pregnancy was classified into two groups: never smoker (did not smoke cigarettes throughout index pregnancy) and ever smoker. Mode of delivery was categorized into cesarean or vaginal delivery. Gestational age was assessed based on both the first day of the last menstrual period and using early antenatal ultrasonography results, as described previously [14]. Preterm birth is defined as gestational age $\leq 37$ weeks [30]. Maternal education was characterized as below high school (HS), up to HS, and above HS.

Placental pathology as a variable was assessed prospectively with each enrollment into the BBC. The details have been previously described [31]. Pathological placental lesions were diagnosed based on commonly used, recommended criteria according to the classification proposed by Redline [32-34]. Broadly, the categories were: CA (chorioamnionitis); maternal vascular malperfusion (MVM); marginal (venous) abruption; umbilical cord obstruction; fetal vascular malperfusion; villous stromal-vascular abnormalities; and a miscellaneous group. For the purpose of this report our reference group was the one with no placental pathological findings (no MVM and no inflammation) and we only focused on MVM and CA as our major placental pathology findings.

Student $t$-test was used to compare continuous variables, and Pearson's Chi-square test was used for categorical variables. Those associations with $P$ values (2-sided tests) less than 0.05 were regarded as statistically significant. Regression analysis was performed by selecting both antenatal and neonatal variables (independent variables) to analyze the effect on the dependent variable which was defined as SGA status at NICU discharge. Multiple stepwise regression analysis (entry criteria: if the $p$ value of the $F$ test was $<0.05$; removal criteria: if the $p$ value of the $F$ test was $>0.10$ ) was also performed to assess the association of covariables chosen. We 
Table 1 Growth status at birth and at NICU discharge.

\begin{tabular}{|c|c|c|c|c|c|c|}
\hline & \multicolumn{3}{|l|}{ Admit } & \multicolumn{3}{|l|}{ Discharge } \\
\hline & SGA & AGA & LGA & SGA & AGA & LGA \\
\hline Fenton growth status for BBC $(n=1063)$ & $70(6.6 \%)$ & $943(88.7 \%)$ & $50(4.7 \%)$ & $231(21.7 \%)$ & $805(75.7 \%)$ & $27(2.6 \%)$ \\
\hline Fenton growth status for BBC Group $1(n=167)$ & $8(4.8 \%)$ & $151(90.4 \%)$ & $8(4.8 \%)$ & $41(24.6 \%)$ & $125(74.9 \%)$ & $1(0.6 \%)$ \\
\hline Fenton growth status for BBC Group $2(n=270)$ & $10(3.7 \%)$ & $246(91.1 \%)$ & $14(5.2 \%)$ & $57(21.1 \%)$ & $206(76.2 \%)$ & $7(2.6 \%)$ \\
\hline Fenton growth status for BBC Group $3(n=626)$ & $52(8.3 \%)$ & $546(87.2 \%)$ & $28(4.5 \%)$ & $133(21.2 \%)$ & $474(75.7 \%)$ & $19(3.1 \%)$ \\
\hline
\end{tabular}

Data presented as counts (percentage), BBC (Boston Birth Cohort).

Included only infants with NICU admission and GA $<37$ weeks.

Group 1: 23 to $\leq 28$ weeks GA.

Group 2: 28 to $\leq 32$ weeks GA.

Group 3: 32 to $\leq 37$ weeks GA.

Table 2 Dynamics of growth pattern from birth to NICU discharge.

Growth status at birth: Growth status at NICU discharge:

$N$ (\% of total cohort) $\quad N$ (\% of birth status)

\begin{tabular}{cccc} 
& \multicolumn{1}{l}{ SGA } & \multicolumn{1}{l}{ AGA } & \multicolumn{1}{l}{ LGA } \\
\hline SGA 70 (6.6\%) & $62(88.6 \%)$ & $7(10.0 \%)$ & $1(1.4 \%)$ \\
AGA 943 $(88.7 \%)$ & $168(17.8 \%)$ & $770(81.7 \%)$ & $5(0.5 \%)$ \\
LGA 50 $(4.7 \%)$ & $1(2 \%)$ & $28(56 \%)$ & $21(42 \%)$ \\
\hline
\end{tabular}

Data presented as counts (percentage).

$B B C$ Boston Birth Cohort.

included some variables which had reached statistical significance and some variables were chosen based on clinical relevance and literature. All statistical analyses were performed using STATA version 15.2 [35].

\section{Results}

1063 maternal-infant dyads were analyzed for this project. We only included infants who were preterm $(\leq 37$ weeks at birth) and who were admitted to NICU. There were 14 neonatal deaths. Cohort mean for gestational age of the infants were 31.9 ( \pm weeks; $60.1 \%$ were black children; $51.5 \%$ were males, and mean $(+\mathrm{SD})$ for NICU stay was $36.7( \pm 32.4)$ days.

At birth $6.6 \%$ infants were SGA (Table 1) but by the time of NICU discharge, $21.7 \%$ were below 10th percentile for weight. Table 1 also depicts the incidence of EUGR when analyzed by gestational age subgroups.

To assess dynamic growth of the infants; growth status was re-evaluated at NICU discharge. $88.6 \%$ of infants who were born SGA continued to be SGA at NICU discharge, $17.8 \%$ of infants born AGA became SGA and $2 \%$ of infants born LGA became SGA at NICU discharge (Table 2).

The relevant baseline demographic characteristics of the cohort are depicted in Supplementary Table 1. Infants born
SGA were born to mothers who were older, nulliparous, and smokers. The risk of birth SGA was lower if mothers had received antenatal steroids (any dose). Placental analysis revealed MVM only was higher and inflammation only was lower in infants born SGA. The relevant clinical characteristics of the cohort based on their birth growth status are depicted in Supplementary Table 2. Clinical characteristics and outcomes for the two groups based on their growth status were statistically different for discharge weight, presence of PDA, sepsis and use of breast milk (BM).

Table 3 depicts the effect of antenatal factors on eventual growth status outcome at NICU discharge (discharge AGA and discharge SGA/EUGR). Birth weight, APGAR scores at 1 and $5 \mathrm{~min}$, maternal education and nulliparity, intrauterine drug exposure and past smoking history correlated with EUGR. Infants with EUGR at NICU discharge had higher MVM only lesions and lower inflammation only as their placental findings.

Table 4 depicts the impact of important clinical covariables of preterm infants in the cohort on their discharge growth status. Infants who had EUGR at NICU discharge had significantly higher incidence of NICU morbidities like use of surfactant, days on ventilator, use of postnatal steroids, chronic lung disease (CLD), retinopathy of prematurity (ROP), and sepsis during their NICU course amongst some other covariables listed in the table. EUGR infants also had longer length of stay in NICU. Delay in DOL of first feed and DOL of achievement of full feeds was also associated with eventual EUGR at NICU discharge.

Regression analysis was carried out by adjusting for both antenatal (placenta findings, intra uterine drug exposure, and use of antenatal steroids) and neonatal (birth weight, gestational age, postnatal steroids, CLD, PDA, sepsis, IVH, NEC, day of first feed and day of full feeds) independent variables. After adjusting, the odds for EUGR status at NICU discharge was only statistically significantly associated with birth weight (OR 0.99, $p=0.00$, CI 0.99-0.99), GA at birth (OR 4.58, $p=0.00$, CI 3.25-6.44), PDA 
Table 3 Antenatal factors associated with SGA status at NICU discharge, BBC.

\begin{tabular}{|c|c|c|c|}
\hline & $\begin{array}{l}\text { Discharge SGA } \\
(n=231)\end{array}$ & $\begin{array}{l}\text { Discharge AGA } \\
(n=805)\end{array}$ & $P$ value \\
\hline Birth weight $(\mathrm{g})^{\mathrm{a}}$ & $1451.87(527.63)$ & $1795.04(633.13)$ & $<0.01$ \\
\hline $\begin{array}{l}\text { Birth head } \\
\text { circumference }(\mathrm{cm})^{\mathrm{a}}\end{array}$ & $28.09(3.44)$ & $29.12(3.17)$ & $<0.01$ \\
\hline Birth length $(\mathrm{cm})^{\mathrm{a}}$ & $40.15(4.85)$ & $42.03(4.77)$ & $<0.01$ \\
\hline $\begin{array}{l}\text { Gestational age (GA) } \\
\text { in weeks }{ }^{\mathrm{a}}\end{array}$ & $32.03(3.58)$ & $31.90(3.17)$ & 0.58 \\
\hline Gender $^{\mathrm{b}}$ & & & 0.28 \\
\hline Male & $112(48.48 \%)$ & $420(52.50 \%)$ & \\
\hline Female & $119(51.52 \%)$ & $380(47.50 \%)$ & \\
\hline 1 min $\mathrm{APGAR}^{\mathrm{a}}$ & $5.64(2.58)$ & $6.14(2.36)$ & 0.03 \\
\hline 5 min $\mathrm{APGAR}^{\mathrm{a}}$ & $7.3(1.98)$ & $7.7(1.46)$ & 0.01 \\
\hline Maternal race ${ }^{\mathrm{b}}$ & & & 0.45 \\
\hline Black & $129(61.14 \%)$ & $334(59.57 \%)$ & \\
\hline Non-Black & $82(38.86 \%)$ & $222(39.71 \%)$ & \\
\hline Maternal age ${ }^{b}$ & & & 0.66 \\
\hline 20-35 (ref) & $143(67.77 \%)$ & $381(68.48 \%)$ & \\
\hline$<20$ & $20(9.48 \%)$ & $53(9.67 \%)$ & \\
\hline$>35$ & $48(22.75 \%)$ & $121(21.85 \%)$ & \\
\hline Maternal education ${ }^{\mathrm{b}}$ & & & $<0.01$ \\
\hline $\begin{array}{l}\text { Above high } \\
\text { school (HS) }\end{array}$ & $74(32.03 \%)$ & $185(22.98 \%)$ & \\
\hline Below HS & $64(27.71 \%)$ & $170(21.12 \%)$ & \\
\hline HS & $73(31.60 \%)$ & $200(24.84 \%)$ & \\
\hline Unknown & $20(8.66 \%)$ & $250(31.06 \%)$ & \\
\hline Maternal parity ${ }^{\mathrm{b}}$ & & & $<0.01$ \\
\hline Nulliparous & $104(45.02 \%)$ & $228(28.32 \%)$ & \\
\hline Multiparous & $107(46.32 \%)$ & $327(40.62 \%)$ & \\
\hline Unknown & $20(8.66 \%)$ & $250(31.06 \%)$ & \\
\hline $\begin{array}{l}\text { Intrauterine drug } \\
\text { exposure }^{\mathrm{b}}\end{array}$ & $30(12.99 \%)$ & $39(4.84 \%)$ & $<0.01$ \\
\hline Ever smoked $^{\mathrm{b}}$ & $66(28.57 \%)$ & $149(18.51 \%)$ & 0.001 \\
\hline $\begin{array}{l}\text { Placenta } \\
\text { information }^{\mathrm{b}}\end{array}$ & & & $<0.01$ \\
\hline $\begin{array}{l}\text { No inflammation } \\
\text { and no MVM (ref.) }\end{array}$ & $73(31.6 \%)$ & $347(43.11 \%)$ & \\
\hline Inflammation only & $27(11.69 \%)$ & $193(23.98 \%)$ & \\
\hline MVM only & $112(48.48 \%)$ & $210(26.09 \%)$ & \\
\hline $\begin{array}{l}\text { Both Inflammation } \\
\text { and MVM }\end{array}$ & $19(8.23 \%)$ & $55(6.83 \%)$ & \\
\hline $\begin{array}{l}\text { Antenatal steroid } \\
\text { (any) }\end{array}$ & $135(21.46 \%)$ & $494(78.54 \%)$ & 0.64 \\
\hline $\begin{array}{l}\text { Doses of antenatal } \\
\text { steroid }^{\mathrm{b}}\end{array}$ & & & $<0.01$ \\
\hline 0 dose & $115(49.78 \%)$ & $531(65.96 \%)$ & \\
\hline 1 dose & $25(10.82 \%)$ & $66(8.20 \%)$ & \\
\hline$\geq 2$ dose & $91(39.39 \%)$ & $208(25.84 \%)$ & \\
\hline
\end{tabular}

Data presented as counts (percentage) or mean (SD).

${ }^{\mathrm{a}} t$-test analysis.

${ }^{b}$ chi square analysis.
Table 4 Clinical characteristics of infants with ex-uterine growth failure assessed at NICU discharge in BBC.

\begin{tabular}{|c|c|c|c|}
\hline & $\begin{array}{l}\text { Discharge SGA } \\
(n=231)\end{array}$ & $\begin{array}{l}\text { Discharge AGA } \\
(n=805)\end{array}$ & $P$ value \\
\hline $\begin{array}{l}\text { Post menstrual age (PMA) at } \\
\text { discharge in weeks }\end{array}$ & $38.6(3.30)$ & $36.9(4.6)$ & $<0.01$ \\
\hline Discharge weight $(\mathrm{g})^{\mathrm{a}}$ & $2308.52(559.17)$ & $2591(534.51)$ & $<0.01$ \\
\hline $\begin{array}{l}\text { Discharge head circumference } \\
(\mathrm{cm})^{\mathrm{a}}\end{array}$ & $33.04(2.58)$ & $34.84(5.02)$ & 0.02 \\
\hline Discharge length $(\mathrm{cm})^{\mathrm{a}}$ & 45.07 (4.49) & 44.49 (5.65) & 0.56 \\
\hline Deaths ${ }^{\mathrm{b}}$ & $7(3.40 \%)$ & $7(1.46 \%)$ & 0.10 \\
\hline Use of any surfactant ${ }^{\mathrm{b}}$ & $43(18.61 \%)$ & $77(9.57 \%)$ & $<0.01$ \\
\hline Number of surfactant doses ${ }^{b}$ & & & 0.003 \\
\hline 0 & $189(81.82 \%)$ & $729(90.56 \%)$ & \\
\hline 1 & $31(13.42 \%)$ & $59(7.33 \%)$ & \\
\hline 2 & $9(3.90 \%)$ & $13(1.61 \%)$ & \\
\hline 3 & $2(0.87 \%)$ & $4(0.5)$ & \\
\hline Ever intubated ${ }^{\mathrm{b}}$ & $95(41.13 \%)$ & $179(22.24 \%)$ & $<0.01$ \\
\hline $\begin{array}{l}\text { Day of life (DOL) of } \\
\text { extubation }\end{array}$ & $24.8(3.7)$ & $13.5(1.6)$ & 0.001 \\
\hline Days on vent ${ }^{\mathrm{a}}$ & $7.2(1.3)$ & $3.6(0.6)$ & 0.004 \\
\hline Use of postnatal steroids ${ }^{b}$ & $20(8.66 \%)$ & $26(3.23 \%)$ & $<0.01$ \\
\hline Chronic lung disease $^{\mathrm{b}}$ & $34(14.78 \%)$ & $49(6.13 \%)$ & $<0.01$ \\
\hline PDA presence ${ }^{\mathrm{b}}$ & $54(23.7 \%)$ & $175(22.01 \%)$ & 0.57 \\
\hline Ligation for $\mathrm{PDA}^{\mathrm{b}}$ & $12(5.19 \%)$ & $15(1.86 \%)$ & 0.14 \\
\hline Presence of Any IVH ${ }^{\mathrm{b}}$ & $45(19.48 \%)$ & $76(9.44 \%)$ & $<0.01$ \\
\hline Severe IVH (Grade III/IV) ${ }^{\mathrm{b}}$ & $7(3.03 \%)$ & $9(1.12 \%)$ & 0.04 \\
\hline $\begin{array}{l}\text { Post hemorrhagic } \\
\text { hydrocephalus }\end{array}$ & $2(0.87 \%)$ & $4(0.50 \%)$ & 0.51 \\
\hline Periventricular leukomalacia $^{\mathrm{b}}$ & $11(4.76 \%)$ & $11(1.37 \%)$ & 0.006 \\
\hline $\mathrm{ROP}^{\mathrm{b}}$ & $36(15.58 \%)$ & $54(6.71 \%)$ & $<0.01$ \\
\hline ROP with plus disease $\mathrm{b}^{\mathrm{b}}$ & $8(3.46 \%)$ & $4(0.5 \%)$ & $<0.01$ \\
\hline ROP needing laser surgery ${ }^{b}$ & $9(3.90 \%)$ & $5(0.62 \%)$ & $<0.01$ \\
\hline $\mathrm{NEC}^{\mathrm{b}}$ & $21(9.09 \%)$ & $46(5.72 \%)$ & 0.06 \\
\hline Perforation ${ }^{\mathrm{b}}$ & $5(2.16 \%)$ & $1(0.12)$ & $<0.01$ \\
\hline Sepsis $^{\mathrm{b}}$ & $69(29.87 \%)$ & $352(43.73 \%)$ & $<0.01$ \\
\hline Episodes of sepsis ${ }^{\mathrm{b}}$ & & & $<0.01$ \\
\hline 0 & $171(74.03 \%)$ & $702(87.20 \%)$ & \\
\hline 1 & $29(12.55 \%)$ & $67(8.32 \%)$ & \\
\hline 2 & $23(9.96 \%)$ & $22(2.73 \%)$ & \\
\hline$\geq 3$ & $8(3.46 \%)$ & $14(1.74 \%)$ & \\
\hline Length of stay (days) ${ }^{\mathrm{a}}$ & $47.26(38.69)$ & $35.53(39.97)$ & $<0.01$ \\
\hline Candida Infection $^{\mathrm{b}}$ & $8(3.46 \%)$ & $6(0.75 \%)$ & 0.002 \\
\hline Presence of central lines ${ }^{\mathrm{b}}$ & $63(27.27 \%)$ & $109(13.54 \%)$ & $<0.01$ \\
\hline DOL of first feed ${ }^{\mathrm{a}}$ & $4.45(11.1)$ & $2.94(4.76)$ & 0.03 \\
\hline Ever received $\mathrm{BM}^{\mathrm{b}}$ & $103(44.59 \%)$ & $194(24.10 \%)$ & $<0.01$ \\
\hline DOL of full feeds ${ }^{\mathrm{a}}$ & $21.10(26.17)$ & $13.05(15.6)$ & $<0.01$ \\
\hline $\mathrm{Kcal} / \mathrm{kg} /$ day at DOL $7^{\mathrm{a}}$ & $95.41(18.27)$ & $99.39(17.90)$ & 0.07 \\
\hline $\mathrm{Kcal} / \mathrm{kg} / \mathrm{day}$ at DOL $14^{\mathrm{a}}$ & $110.16(21.12)$ & $105.31(23.00)$ & 0.25 \\
\hline $\mathrm{Kcal} / \mathrm{kg} /$ day at DOL $21^{\mathrm{a}}$ & $111.39(20.31)$ & $108.71(17.81)$ & 0.43 \\
\hline $\mathrm{Kcal} / \mathrm{kg} /$ day at DOL $28^{\mathrm{a}}$ & $112.46(22.06)$ & $112.44(19.5)$ & 0.99 \\
\hline $\mathrm{Kcal} / \mathrm{kg} /$ day at DOL $35^{\mathrm{a}}$ & 118. (22.63) & $117.07(21.36)$ & 0.84 \\
\hline $\mathrm{Kcal} / \mathrm{kg} /$ day at DOL $42^{\mathrm{a}}$ & $115.59(23.54)$ & $119.98(19.33)$ & 0.77 \\
\hline $\mathrm{Kcal} / \mathrm{kg} /$ day at DOL $49^{\mathrm{a}}$ & $126.08(18.92)$ & $119.93(23.43)$ & 0.27 \\
\hline $\mathrm{Kcal} / \mathrm{kg} / \mathrm{day}$ at DOL $56^{\mathrm{a}}$ & $132.15(15.06)$ & $122(26.24)$ & 0.12 \\
\hline $\begin{array}{l}\mathrm{Kcal} / \mathrm{kg} / \text { day at } 36 \text { weeks } \\
\mathrm{PMA}^{\mathrm{a}}\end{array}$ & $118.75(24.50)$ & 117.25 (19.78) & 0.61 \\
\hline
\end{tabular}

Data presented as counts (percentage) or mean (SD).

${ }^{\mathrm{a}} t$-test analysis.

${ }^{\mathrm{b}}$ chi square analysis. 
(OR 2.9, $p=0.02$, CI 1.17-7.1), NEC (OR 5.14, $p=0.012$, CI 1.44-18.3) and day of life of reaching full feeds (OR 1.04, $p=0.001$, CI 1.01-1.06). On stepwise forward regression analysis EUGR at NICU discharge was statistically significant for day of life at full feeds (OR 1.03, $p=$ 0.00, CI 1.02-1.04), placental findings of MVM only (OR 2.86, $p=0.00$, CI 1.81-4.5) and placental findings of inflammation only (OR $0.36, p=0.00$, CI $0.17-0.34$ ). On stepwise backward regression analysis EUGR at NICU discharge was statistically significant for day of life at full feeds (OR 1.04, $p=0.00$, CI 1.02-1.06), placental findings of MVM only (OR 2.93, $p=0.00$, CI 1.85-4.64) and placental findings of inflammation only (OR $0.36, p=0.003$, CI $0.18-0.71)$.

\section{Discussion}

To our knowledge, this report is among the largest prospectively followed birth cohort study to assess the antenatal and neonatal factors and their association with PGF of preterm infants admitted to NICU. While several studies have reported EUGR in larger samples, they have been limited in their retrospective nature. Clark et al. evaluated 23,371 infants discharged from 124 NICUs and reported that EUGR decreased from $71 \%$ for infants born at 23 weeks to $23 \%$ for those born at 34 weeks [18]. Radmacher et al. reported EUGR rates at discharge to be $59 \%$ [3]. National Institute of Child Health and Human Development Neonatal Research Network study on preterm infants with birth weights of 401-1500 reported that $97 \%$ of these infants had weights less than the 10th percentile at 36 weeks' postmenstrual age [36]. The reported rates of SGA at birth and at NICU discharge by the NICHD study were $16 \%$ and $89 \%$, respectively [4]. EUGR in these larger samples studies have been limited in their lack of detailed antenatal clinical and placental and NICU information as presented in our study. Additionally, none of these studies assessed the racial and socio demographic maternal factors and their role in growth patterns of preterm infants. Overall EUGR in our cohort was $\sim 21 \%$ by discharge (as opposed to SGA of $6.6 \%$ at birth). Our subgroup analysis revealed that the preterm infants born between 23 and $\leq 28$ weeks had the highest rates of EUGR at NICU discharge at 24.6\%. EUGR rates were for infants born between 28-32 weeks and $32-37$ weeks were similar at $21.1 \%$ and $21.2 \%$ respectively. Infants born at the earliest weeks of viability suffer many medical comorbidities in the NICU like infections, severe lung disease, and NEC amongst others. Hence it could be envisioned that this group would suffer the greatest rates of EUGR. Even though the trend of decreased EUGR with increasing GA was similar to other studies the magnitude of this difference between different GA groups was much smaller. We speculate that this could be due to a difference in population characteristics between the published studies and our report. We speculate that this could also be due to slightly larger mean gestational age of the infants analyzed and subsequent less NICU stay and potentially fewer medical complications of prematurity of these larger infants.

Supplementary Table 2 reveals that the nutrition provided for SGA infants was comparable to that provided for AGA infants and so was the day of life full feeds were reached. This indicates that at least for our cohort the difference in outcomes could not be attributed to nutritional practices and nutritional parameters. It will be fair to assume that nutritional approach to infants born SGA vs. AGA did not differ at the outset. However, when analyzed based on the discharge growth status EUGR infants were the ones who had delay in initiation of first feeds and attainment of full feeds (Table 4) The rates of most comorbidities like NEC, BPD, infections suffered by preterm infants were also similar in both SGA and AGA groups (Supplementary Table 2). As is evident in Table 4 medical conditions like, CLD, sepsis amongst others were higher in infants who eventually had EUGR at NICU discharge. This would make biological sense as these are conditions that interrupt nutrition and/or are conditions with increase metabolic needs and potentially alter postnatal growth and are routinely accepted surrogate markers for severity of illness. Our data also demonstrated that EUGR was higher in infants who received postnatal steroids $(8.6 \%$ vs. $3.2 \%)$. This is of concern since numerous studies now show the profound and lasting effects that steroids can have on growth of the lungs, body, and brain [18].

There has been limited data about the relationship between placental pathology and postnatal growth. Some previous studies reported an association between placental pathology and postnatal growth [23-25]. These studies investigated the placentae of premature babies and found that placental inflammation was associated with poor neonatal weight gain [24]. Wang et al. reported that maternal and fetal inflammatory changes in placenta were associated with PGF [24]. Likewise, histological CA was associated with poor neonatal growth in preterm infants born at less than 32 weeks gestational age [23] and the investigators also adjusted for relevant maternal and neonatal variables. Similarly, Redline has reported five patterns of placental injury which were more frequent in subjects with IUGR than in subjects with no IUGR [37]. His study (including preterm infants) found IUGR placentas with maternal vascular obstruction in $47 \%$ of subjects, villitis if unknown etiology in $26 \%$, peri villous fibrin in $17 \%$, fetal vascular obstruction in $11 \%$, and chronic abruption in $8 \%$. Our baseline placental pathology data revealed that MVM only was higher and inflammation only was lower in infants born SGA. We speculate that the lack of correlation between 
inflammatory placental findings and birth SGA status and EUGR on regression analysis could be due to small sample size. When assessed for the primary outcome variable of EUGR, inflammation only placental pathology correlated with lower incidence of EUGR $(11.69 \%$ in EUGR vs. $23.98 \%$ in discharge AGA) and MVM only was correlated with higher incidence of EUGR (48.48\% in EUGR vs. $26.09 \%$ in discharge AGA infants). MVM has been commonly reported in pregnancies complicated with IUGR [38]. Many possible pathways have been described to explain placental malperfusion related fetal growth restriction like smooth muscle oxidative stress, suppression of protein synthesis, unfolded protein response and increase in pro inflammatory cytokines amongst others [39]. There have also been speculations that multiple environment changes may give rise to placental metaflammation or "cold smoldering inflammation" (first hit) and this predisposes the fetus to chronic diseases in life (e.g., BPD) [38, 40]. Whether this effect persists or leads to subsequent longlasting changes that may even suppress neonatal growth even after birth is unknown but we speculate that a similar metaflammation "2 hit process" (comorbidities of prematurity and NICU environment being the second hit) may explain EUGR in our cohort infants and preterm infants overall who have suffered from IUGR.

The major strength of our study is that it is based on a large predominantly urban minority birth cohort. In this birth cohort data were collected prospectively, thus overcoming some drawbacks of retrospective studies, including recall bias and selection bias. Another strength is that this study evaluates the whole continuum of factors that could be associated with the growth failure in preterm infants. We not only analyzed antenatal biological and social factors linked to SGA status at birth; we also evaluated exposures during NICU stay for these preterm infants that could contribute to EUGR. The inclusion and analysis of maternal social factors and their impact (smoking, in utero drug exposure, and education) on eventual growth restriction at NICU discharge is also an important strength of our study. Effect of social influences (including smoking) on birth weight have been well reported [41]. We speculate that these factors also have an impact on postnatal NICU growth through multifactorial interplay of biological and environmental factors. Another strength of our study is detailed nutritional and interval growth data. In future this will allow us to analyze our cohort data to identify early markers of postnatal malnutrition and attempt to validate recent preterm neonatal malnutrition recommendations [42].

Our study has several limitations. The population of BBC (a high-risk minority population, higher GA, and larger BW in this cohort) may not be representative of the larger population comprising younger cohort of NICU graduates. Secondly, the data were collected over a period of 12 years and some aspects of medical and technological advancements in the NICU have occurred over the time period, which might have affected the outcomes of preterm infants including lesser mortality. Hence some of our results may not be applicable to current day clinical management in NICU. Interestingly though in another large study over a similar period of 8 years for preterm infants weighing $501-1500 \mathrm{~g}$ EUGR was reported in $64.5 \%$ and $50.3 \%$ of infants at the beginning and end of study period. Similarly, severe EUGR (defined as wt. >3rd percentile) was 39.8 and $27.5 \%$ for the same study time points. This reflects that even with medical advances half of these preterm infants suffer EUGR and a quarter suffer from severe EUGR [43]. Additionally, there has been recent concerns on use of terms like EUGR and PGF as experts believe that these terms are not predictive of adverse neurodevelopmental outcomes, are based only on weight criteria and do not include body proportionality and are based on arbitrary statistical cutoffs. Experts believe that undue focus on these terms leads to increased nutritional supplementation which may be of harm when provided above the infant's needs [2]. However, until these terms are redefined they will continue to be used objectively as surrogate of growth for preterm infants being discharged from NICU. Another limitation is that we did not report growth patterns during early infancy. Neither did we report long term neurodevelopmental outcomes in preterm infants affected by their NICU growth status. Next, although we did report higher use of postnatal steroids and BPD in EUGR infants we could not capture duration of postnatal steroid and duration of diuretic use. Lastly, we had data collection on total calories intake per kilo per day at important intervals during NICU stay but we lacked in detailed nutritional information like protein and fat calories intake and other details of formula types and fortification.

To conclude, in this sample of urban, low income minority preterm infants, we demonstrated that EUGR remains a significant problem. Around one-fifth of preterm infants are still being discharged with birth weight less than 10th percentile and approximately $20 \%$ of infants born AGA end up being SGA by the time of discharge from NICU. Developing insights into the role of antenatal and neonatal factors in relation to EUGR may aid neonatologists for anticipatory and optimal management of preterm infants and appropriate counselling of parents of such infants regarding growth outcomes.

Funding The Boston Birth Cohort (the parent study, PI, XW) was supported in part by the March of Dimes PERI grants (20-FY02-56, \#21-FY07-605), the Health Resources and Services Administration (HRSA) of the U.S. Department of Health and Human Services (HHS) under grant number R40MC27443, Autism Field-initiated Innovative Research Studies Program; and grant number UJ2MC31074, Autism Single Investigator Innovation Program; and the National Institutes of Health (NIH) grants (R21ES011666, 2R01HD041702, R21HD066471, 
U01AI090727， R21AI079872， R01HD086013， R01HD098232, R21AI154233, and R01ES031272). This information or content and conclusions are those of the author and should not be construed as the official position or policy of, nor should any endorsements be inferred by HRSA, HHS or the US Government.

\section{Compliance with ethical standards}

Conflict of interest The authors declare no competing interests.

Publisher's note Springer Nature remains neutral with regard to jurisdictional claims in published maps and institutional affiliations.

\section{References}

1. Fenton TR, Chan HT, Madhu A, Griffin IJ, Hoyos A, Ziegler EE, et al. Preterm infant growth velocity calculations: a systematic review. Pediatrics. 2017;139. https://doi.org/10.1542/peds.2016-2045.

2. Fenton TR, Cormack B, Goldberg D, Nasser R, Alshaikh B, Eliasziw M, et al. 'Extrauterine growth restriction' and 'postnatal growth failure' are misnomers for preterm infants. J Perinatol. 2020. https://doi.org/10.1038/s41372-020-0658-5.

3. Radmacher PG, Looney SW, Rafail ST, Adamkin DH. Prediction of extrauterine growth retardation (EUGR) in VVLBW infants. J Perinatol. 2003;23:392-5.

4. Dusick AM, Poindexter BB, Ehrenkranz RA, Lemons JA. Growth failure in the preterm infant: can we catch up? Semin Perinatol. 2003;27:302-10.

5. Ordóñez-Díaz MD, Pérez-Navero JL, Flores-Rojas K, OlzaMeneses J, Muñoz-Villanueva MC, Aguilera-García CM, et al. Prematurity with extrauterine growth restriction increases the risk of higher levels of glucose, low-grade of inflammation and hypertension in prepubertal children. Front Pediatr. 2020;8:180.

6. Martínez-Jiménez MD, Gómez-García FJ, Gil-Campos M, PérezNavero JL. Comorbidities in childhood associated with extrauterine growth restriction in preterm infants: a scoping review. Eur J Pediatr. 2020;179:1255-65.

7. Clayton PE, Cianfarani S, Czernichow P, Johannsson G, Rapaport R, Rogol A. Management of the child born small for gestational age through to adulthood: a consensus statement of the International Societies of Pediatric Endocrinology and the Growth Hormone Research Society. J Clin Endocrinol Metab. 2007;92:804-10.

8. Larroque B, Bertrais S, Czernichow P, Léger J. School difficulties in 20-year-olds who were born small for gestational age at term in a regional cohort study. Pediatrics. 2001;108:111-5.

9. Leger J, Levy-Marchal C, Bloch J, Pinet A, Chevenne D, Porquet $\mathrm{D}$, et al. Reduced final height and indications for insulin resistance in 20 year olds born small for gestational age: regional cohort study. BMJ. 1997;315:341-7.

10. Ehrenkranz RA, Dusick AM, Vohr BR, Wright LL, Wrage LA, Poole WK. Growth in the neonatal intensive care unit influences neurodevelopmental and growth outcomes of extremely low birth weight infants. Pediatrics. 2006;117:1253-61.

11. Regan FM, Cutfield WS, Jefferies C, Robinson E, Hofman PL. The impact of early nutrition in premature infants on later childhood insulin sensitivity and growth. Pediatrics. 2006;118:1943-9.

12. Singhal A. Early nutrition and long-term cardiovascular health. Nutr Rev. 2006;64:S44-9.

13. Singhal A, Cole TJ, Fewtrell M, Deanfield J, Lucas A. Is slower early growth beneficial for long-term cardiovascular health? Circulation. 2004;109:1108-13.
14. Wang X, Zuckerman B, Pearson C, Kaufman G, Chen C, Wang $\mathrm{G}$, et al. Maternal cigarette smoking, metabolic gene polymorphism, and infant birth weight. JAMA. 2002;287:195-202.

15. Saenger P, Reiter E. Genetic factors associated with small for gestational age birth and the use of human growth hormone in treating the disorder. Int J Pediatr Endocrinol. 2012;2012:12.

16. Houk CP, Lee PA. Early diagnosis and treatment referral of children born small for gestational age without catch-up growth are critical for optimal growth outcomes. Int J Pediatr Endocrinol. 2012;2012:11.

17. Ehrenkranz RA, Younes N, Lemons JA, Fanaroff AA, Donovan EF, Wright LL, et al. Longitudinal growth of hospitalized very low birth weight infants. Pediatrics. 1999;104:280-9.

18. Clark RH, Thomas P, Peabody J. Extrauterine growth restriction remains a serious problem in prematurely born neonates. Pediatrics. 2003;111:986-90.

19. Shan HM, Cai W, Cao Y, Fang BH, Feng Y. Extrauterine growth retardation in premature infants in Shanghai: a multicenter retrospective review. Eur J Pediatr. 2009;168:1055-9.

20. Ehrenkranz RA. Extrauterine growth restriction: is it preventable? J. Pediatr. 2014;90:1-3.

21. Dinerstein A, Nieto RM, Solana CL, Perez GP, Otheguy LE, Larguia AM. Early and aggressive nutritional strategy (parenteral and enteral) decreases postnatal growth failure in very low birth weight infants. J Perinatol. 2006;26:436-42.

22. McCallie KR, Lee HC, Mayer O, Cohen RS, Hintz SR, Rhine WD. Improved outcomes with a standardized feeding protocol for very low birth weight infants. J Perinatol. 2011;31:S61-7.

23. Trevisanuto D, Peruzzetto C, Cavallin F, Vedovato S, Cosmi E, Visentin S, et al. Fetal placental inflammation is associated with poor neonatal growth of preterm infants: a case-control study. J Matern Fetal Neonatal Med. 2013;26:1484-90.

24. Mestan K, Yu Y, Matoba N, Cerda S, Demmin B, Pearson C, et al. Placental inflammatory response is associated with poor neonatal growth: preterm birth cohort study. Pediatrics. 2010;125:e891-8.

25. Tachibana M, Nakayama M, Ida S, Kitajima H, Mitsuda N, Ozono $\mathrm{K}$, et al. Pathological examination of the placenta in small for gestational age (SGA) children with or without postnatal catch-up growth. J Matern Fetal Neonatal Med. 2016;29:982-6.

26. Barker DJ. Fetal origins of coronary heart disease. BMJ. 1995;311:171-4

27. Wang L, Wang X, Laird N, Zuckerman B, Stubblefield P, Xu X. Polymorphism in maternal LRP8 gene is associated with fetal growth. Am J Hum Genet. 2006;78:770-7.

28. Fenton TR, Kim JH. A systematic review and meta-analysis to revise the Fenton growth chart for preterm infants. BMC Pediatr. 2013;13:59.

29. Kumar P, Venners SA, Fu L, Pearson C, Ortiz K, Wang X. Association of antenatal steroid use with cord blood immune biomarkers in preterm births. Early Hum Dev. 2011;87:559-64.

30. World Health Organization. ICD-10: International statisti-cal classification of diseases and related health problems, 10th revision. Volume 2. 2nd ed. Geneva: WHO; 2004. http://www.who. int/classifications/icd/ICD-10_2nd_ed_volume2.pdf.

31. Bustamante Helfrich B, Chilukuri N, He H, Cerda SR, Hong X, Wang $G$, et al. Maternal vascular malperfusion of the placental bed associated with hypertensive disorders in the Boston Birth Cohort. Placenta. 2017;52:106-13.

32. Langston C, Kaplan C, Macpherson T, Manci E, Peevy K, Clark $\mathrm{B}$, et al. Practice guideline for examination of the placenta: developed by the Placental Pathology Practice Guideline Development Task Force of the College of American Pathologists. Arch Pathol Lab Med. 1997;121:449-76.

33. Redline RW. The clinical implications of placental diagnoses. Semin Perinatol. 2015;39:2-8. 
34. Redline RW. Classification of placental lesions. Am J Obstet Gynecol. 2015;213:S21-8.

35. StataCorp. Stata Statistical Software: Release 15. College Station, TX: StataCorp LLC; 2017.

36. Lemons JA, Bauer CR, Oh W, Korones SB, Papile LA, Stoll BJ, et al. Very low birth weight outcomes of the National Institute of Child health and human development neonatal research network, January 1995 through December 1996. NICHD Neonatal Research Network. Pediatrics. 2001;107:E1.

37. Redline RW. Placental pathology: a systematic approach with clinical correlations. Placenta. 2008;29:S86-91.

38. Ernst LM. Maternal vascular malperfusion of the placental bed. APMIS. 2018;126:551-60.
39. Burton GJ, Jauniaux E. Pathophysiology of placental-derived fetal growth restriction. Am J Obstet Gynecol. 2018;218:S745-S761.

40. Burton GJ, Fowden AL, Thornburg KL. Placental origins of chronic disease. Physiol Rev. 2016;96:1509-65.

41. Spencer N, Logan S. Social influences on birth weight. J Epidemiol Community Health. 2002;56:326-7.

42. Goldberg DL, Becker PJ, Brigham K, Carlson S, Fleck L, Gollins L, et al. Identifying malnutrition in preterm and neonatal populations: recommended indicators. J Acad Nutr Diet. 2018;118:1571-82.

43. Horbar JD, Ehrenkranz RA, Badger GJ, Edwards EM, Morrow $\mathrm{KA}$, Soll RF, et al. Weight growth velocity and postnatal growth failure in infants 501 to 1500 grams: 2000-2013. Pediatrics. 2015;136:e84-92. 